\title{
VIVIR Y MORIR EN MADRID: LA VIVIENDA COMO FACTOR DETERMINANTE DEL ESTADO DE SALUD DE LA POBLACIÓN MADRILEÑA (1874-1923)*
}

\author{
Rafael Huertas
}

Dpto. Historia de la Ciencia, IH, CSIC, Madrid

\section{RESUMEN}

Se analiza el papel de la vivienda como factor determinante del estado de salud de la población madrileña en el tránsito del siglo XIX al XX. A través de los informes y demás aportaciones de higienistas y médicos sociales, se pone de manifiesto cómo la vivienda insalubre en Madrid incidió de manera negativa en la mortalidad y morbilidad de sus habitantes, siendo motivo de preocupación de médicos, urbanistas y políticos. Se apunta, asimismo, de qué manera el problema de la vivienda insalubre pasa a formar parte de la llamada cuestión social y las propuestas de intervención que, siempre en el marco de los principios de la higiene liberal, intentó aunar actuaciones de salud pública y de política urbanística.

PALABRAS CLAVE: Madrid, vivienda insalubre, salud pública, siglos XIX-XX.

\section{SUMMARY}

This paper analyses the role of housing as determining factor for the welfare of Madrid's population during the change of the XIXth century to the XXth century. Through medical reports and the contributions of hygienists and social physicians, it will be demonstrated that unhealthy housing in Madrid became a negative factor for the mortality and the morbidity of its residents, in such a way that it made physicians, town planners, and politicians to be preocupied. It will also be discussed how this problem of unhealthy housing started to take part of the so-called social question and the proposals for intervention always framed within the principles of the liberal hygiene, -which intented to combine public health and town planning politics.

KEY WORDS: Madrid, unhealthy housing, public health, $19^{\text {th }}$ and $20^{\text {th }}$ centuries.

* Trabajo realizado en el marco del Proyecto de Investigación n ${ }^{\circ}$ 06/0022/1997, subvencionado por el Plan Regional de la Comunidad de Madrid 


\section{INTRODUCCION}

La identificación de Madrid como «ciudad de la muerte» fue frecuente en textos médicos, informes oficiales y artículos de prensa referidos a los últimos años del siglo XIX ${ }^{1}$. No era para menos, las tasas de mortalidad general e infantil durante las últimas décadas del siglo XIX superaron con creces las de otras capitales europeas, no solo debido a las epidemias que cíclicamente atacaban a la población madrileña, sino también a las endemias $y$, en general, al pésimo nivel de salud de la población madrileña en situaciones no epidémicas. Sin embargo, la denominación de «ciudad de la muerte» cobraba todo su significado al constatarse que, a partir de $1880 \mathrm{y}$ hasta 1902, son mayoría los años en los que las tasas de mortalidad superan con creces las de natalidad. Un crecimiento vegetativo negativo que fue apuntado con alarma por autores de la época ${ }^{2}$, y que es considerado por la historiografía actual como el indicador clave que traduce las difíciles condiciones de vida de gran parte de la población de la Villa 3 .

Las epidemias de cólera de $1834^{4}, 1854-56^{5}, 1865$ y $1885^{6}$ han sido objeto de estudios diversos y constituyen, sin duda, un referente historiográfico de gran interés para la historia social de la medicina y de la salud, aun cuando está demostrado que el cólera de 1885 no tuvo consecuencias tan catastróficas, en cuanto a las tasas de mortalidad, como otras epidemias que asolaron la Villa en la última década del siglo, así las de viruela de 1889, 1896 y 1900, o la de sarampión de 1895. Mención especial merece el año 1890, en el que la viruela y la gripe se cobraron más víctimas que en cualquier otro brote epidémico ${ }^{7}$. Es significativo el comentario de un columnista, en

\footnotetext{
1 La expresión se debe a REVEnga, R. (1901), La muerte en Madrid, Madrid, Dirección General de Sanidad.

2 A modo de ejemplos suficientemente significativos, citaré REVENGA, R. (1901), La muerte en Madrid, Madrid, Dirección General de Sanidad, pp. 9 y ss. También HAUSER, Ph. (1902), Madrid bajo el punto de vista médico-social, Madrid. La edición utilizada ha sido la preparada por Carmen del Moral, Madrid, Editora Nacional, 1979. Las referencias al crecimiento vegetativo negativo pueden encontrarse en vol. I, pp. 494 y ss.

3 Véase FERNANDEZ, A. (1989), «La población madrileña entre 1876 y 1931. El cambio de modelo demográfico», En BAHAMONDE, A. y OTERO, L.E. (eds.), La sociedad madrileña durante la Restauración. 1876-1931, Madrid, Comunidad de Madrid-Alfoz, vol. I, pp. 29-76, p. 35.

4 Véase PUERTO, F.J. y SAN JuAn, C. (1980), «la epidemia de cólera de 1834 en Madrid», Estudios de Historia Social, 15: 9-61. Referido al ámbito no madrileño, véase RODRIGUEZ OCAÑA, E. (1983), El cólera de 1834 en Granada. Enfermedad catastrófica y crisis social, Granada, Universidad de Granada.

5 URQUIJO, J.R. (1980), «Condiciones de vida y cólera: la epidemia de 1854-56 en Madrid», Estudios de Historia Social, 15: 63-142.; URQUIJO, J.R. (1984), La revolución de 1854 en Madrid, Madrid, CSIC.

6 FERnÁndeZ, A, (1985), Epidemias y sociedad en Madrid, Madrid, Vicens-Vives.

7 Ibid., pp. 155 y ss.
} 
aquel año aciago de 1890, al aludir a «la ciudad triste», para referirse al Madrid de la muerte, al Madrid «que no ríe», al Madrid «sin aire, sin agua, sin luz»».

Entre 1902 y 1920, se produce lo que Antonio Fernández ha identificado como un «ciclo de transición demográfica» ${ }^{9}$, en el que las tasas de mortalidad general van descendiendo, aunque persiste una mortalidad infantil elevada y tiene lugar la gran epidemia de gripe de 1918-1910. En este periodo de tiempo todavía pueden registrarse años con crecimiento vegetativo negativo, aunque la tendencia se detiene claramente a partir de 1921.

Es evidente que el descenso de la mortalidad aparece como un elemento fundamental - aunque no el único - para poder explicar la transformación demográfica de las sociedades europeas tradicionales. Otros dos conceptos aparecen íntimamente ligados al de esta transición demográfica: el de transición epidemiológica, entendida como el proceso de cambio del perfil epidemiológico de la población, motivado por las transformaciones en las causas de la morbi-mortalidad ${ }^{11}$; y el de transición sanitaria, que hace referencia al proceso de cambio temporal que se ha producido en relación con los factores que determinan las condiciones de salud y enfermedad de una población y, por tanto, los determinantes que han hecho posible, a través de su modificación, control o reducción, el descenso de la mortalidad ${ }^{12}$.

El concepto de transición sanitaria es importante porque permite tener en cuenta indicadores cualitativos y factores socio-económicos y culturales en el proceso saludenfermedad ${ }^{13}$; de hecho, cuando se habla de elevadas tasas de mortalidad general, sin tener en cuenta otros indicadores cualitativos, se puede cometer el error -o la falacia- de ignorar o de enmascarar las causas sociales del enfermar. Hasta la última década del siglo XIX, no se tiene conciencia clara de que la sobremortalidad de los habitantes de Madrid se produce a expensas de un sector concreto de la población: la

8 BURELl, J., «La ciudad triste», El Imparcial, 3 de noviembre de 1890. Tomado de FERNÁNDEZ, A. (1985), Epidemias y sociedad en Madrid, Madrid, Vicens-Vives, p. 229.

9 FERNÁNDEZ (1989), p. 33.

10 PORRAS, M.I. (1997), Un reto para la sociedad madrileña: la epidemia de gripe de 1918-19, Madrid, Ed. Complutense/Comunidad de Madrid.

11 Sobre este concepto, véase OMRAN, A.R. (1971), «The epidemiologic transition: a theory of the epidemiology of population change», The Milbank Quaterly, 49: 509-583. También TERRIS, M. (1980), La revolución epidemiológica y la medicina social, Madrid, Siglo XXI.

12 Véase Frenk, J., Bobadilla, J.L., Stern, C, FreJKa, T. y LozAno, R. (1991), «Elements for a theory of the health transition», Health Transition Review, 1: 21-38. También ROBLES, E.; BERNABEU, J. y BENAVIDES, F.G. (1996), «La transición sanitaria: una revisión conceptual», Boletón de la Asociación de Demografia Histórica, 14 (1): 117-144; BERNABEU, J. (1996), «Transición sanitaria y evolución de la medicina (diagnóstico, profilaxis y terapéutica), Studi di Popolazione. Temi di Ricerca Nuova, Roma, La Sapienza, pp. 131-145.;

13 Véase Robles, E., Perdiguero, E. y Bernabeu, J. (2000), «De qué hablamos cuando hablamos de factores culturales desde la demografía y epidemiología históricas», En PERDIGUERO, E. y COMELLES, J.M. (eds.), Medicina y cultura. Estudios entre la antropología y la medicina, Barcelona, Bellaterra, pp. 45-53. 
clase trabajadora. Está suficientemente demostrado que las tasas de mortalidad de la burguesía y de las clases «altas» eran similares, e incluso inferiores, a las de la misma clase social de otros países europeos. La consideración de la sociedad madrileña en su conjunto, permitía que el debate sanitario se circunscribiera a aspectos poco comprometidos como el clima, la topografía, etc; sin embargo, la sobremortalidad obrera acabó constituyendo un problema sanitario, social y político imposible de obviar ${ }^{14}$. No se trataba, pues, de ver la manera de hacer frente a la elevada mortalidad de los madrileños, sino de los obreros madrileños y, por extensión, de sus clases populares.

A mi juicio, dicha acotación es fundamental porque permite valorar y analizar los factores determinantes del estado de salud de la población desde una perspectiva dialéctica, centrada en el modo y condiciones de vida, verdadero elemento diferenciador del riesgo de enfermar y morir.

Ya en otros lugares he insistido en la utilidad, en el campo de la Historia de la Salud, de categorías de análisis como el estado de salud de la población y sus factores determinantes $^{\mathbf{1 5}}$. El «estado de salud de la población» viene a expresar sintéticamente, para un momento histórico concreto, el nivel alcanzado en la relación del hombre con la naturaleza y entre los propios hombres respecto a su salud en el plano físico, mental y social» ${ }^{16}$. Los factores determinantes del estado de salud de la población suelen englobarse habitualmente en cuatro grandes grupos: 1) la propia biología humana; 2) el modo y condiciones de vida (el medio social); 3) el medio ambiente físico; y 4) la organización de la Salud Pública. Influidos, todos ellos, por el tipo de organización económico-social y por el grado de desarrollo científico-técnico.

$\mathrm{Si}$ aceptamos el modo de vida como la «categoría sociológica que refleja de forma sistemática las condiciones económicas, sociopolíticas y culturales de las formas características, repetidas y estables de la vida cotidiana de las personas y de las colectividades $\gg{ }^{17}$, no es difícil comprender que a cada clase social le corresponde un determinado «modo de vida». Las diferencias son bien conocidas y se expresan tanto

14 Diversos trabajos se han ocupado de esta cuestión; destacaré entre ellos GARCÍA GÓMEZÁlvareZ, A. (1992), «La sobremortalidad de la clase obrera madrileña a finales del siglo XIX (18801900); FERNÁNDEZ, A. (1992), "Clase obrera y tuberculosis en Madrid a principios del siglo XX», publicados ambos en HUERTAS, R. y CAMPOS, R. (coords.), Medicina social y clase obrera en España (siglos $X I X$ y $X X)$, Madrid, FIM, t. I., pp. 145-176 y 93-124 respectivamente.

15 Tal propuesta teórica puede encontrarse en HUERTAS, R. (1996), «Las ciencias de la salud y el marxismo: sobre la construcción de una teoría de lo social en medicina», Papeles de la FIM, 5 (20 época): 35-45. También HUERTAS, R. (1995), Organización sanitaria y crisis social en España. La discusión sobre el modelo de servicios sanitarios públicos en el primer tercio del siglo XX, Madrid, FIM; HUERTAS, R. (1998), Neoliberalismo y politicas de salud, Madrid, Viejo Topo.

16 Aldereguía, J. (1986), Problemas de Higiene social y Organización de la Salud Pública, La Habana, Científico-Técnica, pp. 44.

17 FilipeC. J. (1985), El modo de vida en la lucha ideológica contemporánea, La Habana, Ciencias Sociales. 
en hábitos higiénicos, composición de la alimentación, calidad de las viviendas, etc., como en las formas en que las personas hacen o no suyas las influencias ejercidas por los valores, ideales y objetivos de las clases en conflicto. Todos estos aspectos hacen referencia, como es obvio, al concepto gramsciano de hegemonía social y su concreción, en cada momento histórico, expresa el nivel alcanzado por la lucha de clases.

Conflictos de clase ante los que higienistas, médicos sociales y demás reformadores sociales intervineron activamente con dos objetivos evidentes: Por una parte, para proponer y defender medidas que atenuasen las duras condiciones de vida y de trabajo del proletariado, cuyo correlato inmediato debía ser la disminución de la mortalidad; por otra, para proponer y llevar a cabo estrategias de tutela y vigilancia de los sectores populares, con el fin de paliar la tensión social generada por la miseria y el pauperismo y la «peligrosidad» tradicionalmente achacada a trabajadores y clases populares. Este papel de «mediadores», «intermediarios» o «árbitros», desempeñado por los médicos e higienistas en el marco de la llamada «cuestión social» ha sido apuntado con acierto por diversos autores ${ }^{18}$, y es, en muy buena medida, al que me voy a referir en el caso concreto de la higiene madrileña.

En el presente ensayo intentaré analizar algunas de las características más sobresalientes de la transición sanitaria en el Madrid del cambio de siglo, con el objetivo de contribuir a la mejor comprensión de la aludida transición demográfica acaecida en la capital del Estado durante la Restauración. Me centraré, para ello, en el análisis de la vivienda como factor determinante del estado de salud de la población madrileña, por entender que la vivienda insalubre y las penosas condiciones urbanísticas de los barrios populares ocuparon un espacio trascendental en el discurso y en los debates sanitarios de Madrid en la época objeto de nuestro estudio.

Utilizaré como fuentes prioritarias, aunque no exclusivas, los Informes y demás aportaciones de higienistas y médicos sociales. Soy consciente - me apresuro a aclararlo- que el tema no se agota con el estudio de las fuentes «médicas», y que tendría que completarse con otro tipo de documentos, como los procedentes del movimiento obrero o de las administraciones provincial y municipal referidos a sanidad, urbanismo, vivienda, abastos, infraestructuras, etc.

\footnotetext{
18 Existe una amplia bibliografía al respecto, entre la que señalaré PÉREZ-FUENTES, P. (1991), «El discurso higienista y la moralización de la clase obrera en la primera industrialización vasca», Historia Contemporánea, 5: 127-156.; RodRíGUEZ OCAÑA, E. (1992), «Paz, trabajo, higiene. Los enunciados acerca de la Higiene Industrial en la España del siglo XIX», En HUERTAS, R. y CAMPOS, R. (coords.), Medicina social y clase obrera en España (siglos XIX y XX), Madrid, FIM, t. II, pp. 383-426.; CAMPOS, R. (1995), «La sociedad enferma: Higiene y moral en España en la segunda mitad del siglo XIX y principios del XX», Hispania, 192 (3): 1093-1112.
} 


\section{LA VIVIENDA INSALUBRE}

En un trabajo presentado en 1845 en la Sociedad Económica Matritense, Pedro Felipe Monlau insistía ya en la necesidad para el pobre de «una habitación aireada, limpia y decente» ${ }^{19}$. Sin embargo, la preocupación de los higienistas españoles por las viviendas insalubres - que se puede rastrear en aportaciones de diversos autores - cristaliza en el último tercio del siglo XIX con sendos discursos pronunciados en la Academia de Medicina de Madrid en 1874, con motivo del ingreso en la misma de Rogelio Casas Batista, que venía a cubrir la vacante que, tras su muerte, había dejado el propio P.F. Monlau. Tanto el discurso de Casas Batista ${ }^{20}$, como el de F. Méndez Álvaro, encargado de la preceptiva contestación al nuevo candidato, constituyen dos documentos de excepcional interés para el tema que nos ocupa. Ambos autores, insisten en la influencia de las condiciones de la vivienda en la salud de sus habitantes. La cuestión fundamental es planteada por Méndez Álvaro con claridad: «Mucho importa determinar hasta qué punto es la mayor mortalidad de las clases pobres imputable a las malas condiciones de los aposentos que ocupan» ${ }^{21}$. A partir de este objetivo general, los autores abordaron el problema higiénico de la vivienda obrera.

Los higienistas describen la insalubridad de las viviendas obreras, identificando los principales problemas sanitarios de las mismas; el acuerdo, en este sentido, suele ser bastante unánime: la humedad, la falta de luz y ventilación,..., pero es, sobre todo, el hacinamiento - derivado de la mala distribución de los espacios en el interior de las viviendas - el que con mayor insistencia se repite. «Millares de individuos» — nos dice Casas Batista - «se cobijan, más bien que viven, en cuartos sin más pieza que una, que así suele servir para una sola persona como para toda la familia, y a veces dos, produciéndose amontonamiento de seres, tan fatal para el cuerpo como para el alma» ${ }^{22}$.

19 MonlaU, P.F. [1845] (1979), «Remedios del pauperismo. Memoria para optar al premio ofrecido por la Sociedad Económica Matritense el 1 de mayo de 1845», Estudios de Historia Social, 10-11: 374385, p. 380. Sobre Monlau, véase SÁnCHEZ-GranJel, M. (1983), Pedro Felipe Monlau y la Higiene española del siglo XIX, Salamanca, Universidad de Salamanca.También JUTGLAR, A. (1984), Condiciones de vida y trabajo obrero en España a mediados del siglo XIX, Barcelona, Anthropos, pp. 8-55.

20 CASAS BATISTA, R. (1874), El problema relacivo al hogar del obrero, tanto considerado por sí mismo como en su historia a través de la sucesión de las edades y los pueblos, Discursos de la Academia de Medicina.

21 Méndez Álvaro, F. (1874), De la habitación del menesteroso considerado bajo el aspecto higiénico-social, Discursos de la Academia de Medicina, p. 242. La insistencia de este autor en la relación directa entre la mortalidad de las clases pobres en los grandes centros urbanos y las malas condiciones de sus viviendas se remonta a bastantes años antes, fundamentalmente en su trabajo MÉNDEZ ÁLVARO, F. (1853), Consideraciones sobre la Higiene Pública y mejoras que reclama en España la Higiene Municipal, Madrid, Imp. de José Rodríguez. Sobre este importante higienista véase MoRO, J. (1986), Francisco Méndez Alvaro. La higiene española del siglo XIX, Valladolid, Junta de Castilla y León; FRESQUeT, J.L. (1990), Francisco Méndez Alvaro (1806-1883) y la ideas sanitarias del liberalismo moderado, Madrid, Ministerio de Sanidad y Consumo.

22 CASAS (1874), p. 190. 
La consecuencia inmediata de tal hacinamiento es la escasez de aire respirable en dichos espacios. La enumeración de causas que contribuyen a esta pobreza de oxígeno resulta suficientemente elocuente, y nos permite obviar cualquier comentario: «las alteraciones del ambiente por la respiración, exhalación y escreciones, el consumo del oxígeno y desprendimiento de ácido carbónico, por la combustión necesaria para la preparación del alimento, encerrada no pocas veces en la única habitación; los variados materiales empleados para mantener el fuego, la paja, el estiercol, la madera y el carbón o la leña; la acumulación de ropa sucia o húmeda, tan frecuente donde hay niños de corta edad; los vapores tan cargados de amoniaco, desprendidos al secarse estas piezas de vestir; el depósito de sustancias vegetales o animales en la misma habitación o en otra íntimamente unida; todo lo cual determina alteraciones en el aire, que actuan con variada influencia sobre la salud del que vive en estos reducidos aposentos» ${ }^{23}$.

Con parecidas palabras se expresa Méndez Álvaro, añadiendo: «la suciedad del exterior de las casas, lo elevado de la temperatura en el estío, favoreciendo la descomposición de las sustancias orgánicas, las fugas de gas del alumbrado o el tufo del aceite, etc., hacen de cada calle un insoportable foco de corrupción» ${ }^{24}$. Observación importante, ya que «no solamente en el interior de la casa del pobre abundan las causas de insalubridad que a la higiene toca estudiar y advertir: generalmente se halla situada en los cuarteles, distritos y barrios de las poblaciones grandes que peores condiciones higiénicas reunen; en casas que encierran y condensan las más poderosas causas de insalubridad, formando otros tantos focos de pestilencia» ${ }^{25}$.

En Madrid, los espacios urbanos más insalubres siempre se identificaron con los llamados «barrios del Sur», situados intra o extramuros de la ciudad: Peñuelas, El Salitre, Santa María de la Cabeza, el Cristo de la Injurias, eran —en 1874- barrios destinados a pobres en los que se cumplían todas las condiciones antes aludidas de hacinamiento, limitada e inconveniente distribución de los espacios en el interior de las viviendas, escasez de infraestructuras, falta de aseo particular y urbano, etc. La otra cara de la moneda está representada por el barrio de Argüelles, al noroeste de la capital, «destinado en su mayoría a edificios aislados, de elegante construcción, con jardines o patios exteriores», y, naturalmente, el de Salamanca, al nordeste, «con excelentes condiciones higiénicas y con una construcción tipo, bajo el punto de vista de comodidad y ventilación,...»; si bien es obligado señalar que dicha barriada «no se ha construido para las clases inferiores, sino para la clase media» ${ }^{26}$.

Barrios pobres y barrios acomodados, cuyos indicadores sanitarios acabarán relacionando enfermedad y clase social. La división administrativa de Madrid en distritos

\footnotetext{
23 Ibid., p. 191.

24 MÉNDEZ ÁlVARO (1874), p. 245

25 Ibid., p. 243.

26 CASAS (1874), p. 199-200.
} 
fue utilizada por los higienistas de la época y, posteriormente, por diversos historiadores de la Salud, para acercarse a la realidad sanitaria de los distintos estratos sociales que habitaban la capital del Estado. Cierto es que los datos obtenidos son indirectos y, en algunos casos, requieren ciertos reajustes pues, como bien ha indicado Alfredo García, los distritos madrileños no son homogéneos, ya que su división no responde a criterios sociales sino administrativos, por lo que en los distritos considerados de ricos o de pobres pueden encontrarse viviendas y calles que no se correspondan con las características generales. Además, en el Madrid de cambio de siglo, existían edificios donde convivían clase sociales diferentes (propietarios, profesionales, artesanos, jornaleros, servicio doméstico), aun cuando dicha convivencia estuviera perfectamente jerarquizada y «separada» en los pisos del inmueble ${ }^{27}$.

Conviene aclarar, igualmente, que el Madrid del cambio de siglo no puede considerarse aún una ciudad industrializada sino, en todo caso, como «la superposición de una estructura preindustrial a un incipiente proceso de industrialización». Como ya he indicado, durante los primeros años del siglo XX, Madrid a duras penas comienza a recuperar un crecimiento vegetativo - que en algunos años sigue siendo negativo-, por lo que es el importante flujo migratorio desde la zonas rurales la verdadera causa del encarecimiento de la vivienda y del hacinamiento en los barrios más «económicos» ${ }^{28}$.

Con todo, podemos aventurar una división «social» de Madrid por distritos: La clase obrera o, si se prefiere, las clases populares madrileñas tendían a agruparse, ya lo he indicado, en «los barrios del sur», en los distritos de Inclusa, Latina y Hospital - aunque también en el de Universidad (Vallehermoso, Cuatro Caminos), situado al norte- Dichos «barrios del sur» recibían también el apelativo de «barrios bajos» tanto en un sentido topográfico como social, así lo indican los antropólogos Bernaldo de Quirós y Llanas cuando aseguran que «los llamados barrios bajos de Madrid, localizados en los tres distritos del Hospital, la Latina y la Inclusa, no solo merecen tal nombre por hallarse topográficamente bajo el nivel medio del suelo de la población, sino a la vez, porque considerados demográfica y socialmente acusan la misma inferioridad en el promedio de la urbanización y la cultura madrileña» ${ }^{29}$.

La burguesía habitaba, en general, en los distritos de Centro, Congreso y Audiencia, pero empezaba a ocupar también el citado barrio de Salamanca, en el distrito de

27 Véase GARCía GómeZ-ÁlVAREZ (1992), pp. 154 y ss.

28 El precio de los alquileres se ha utilizado con éxito como un indicador que permite realizar mapas sociales fiables. Véase, a modo de ejemplo, Tusell, J. (1969), Sociología electoral en Madrid. 19031931, Madrid, Edicusa, pp. 22 y ss.; y, en el tema que nos ocupa, FERNÁNDEZ, A. (1987), «Niveles de vida del proletariado madrileño (1883-1903)», en El reformismo social en España. Actas del los IV Coloquios de Historia, Córdoba, Cajasur.

29 BERNALdo DE Quirós, C. y LlanAS, J.M. (1901), La mala vida en Madrid. Estudio psicosociológico, Madrid, Rodríguez Serra Editor, pp. 123-124. 
Buenavista. En los dos distritos restantes (Palacio y Hospicio) parecía existir, a juzgar por los datos disponibles, más mezcla de clases sociales en su población. Como es sabido, en 1902, se lleva a cabo una modificación administrativa (aprobada en 1898 por el Ayuntamiento de Madrid, siendo alcalde Alberto Aguilera), en el que se introduce un distrito más: el de Chamberí — por desdoblamiento del de Hospicio-, en el que conviven algunas zonas obreras con otras más acomodadas.

La recopilación de indicadores sanitarios por distritos ofrecen, pues, una idea bastante aproximada de la realidad socio-sanitaria del Madrid del cambio de siglo. En general, dichas investigaciones han comparado indicadores como mortalidad general $^{30}$, o mortalidad por patologías tanto endémicas ${ }^{31}$, como epidémicas ${ }^{32}$. No se disponen, sin embargo, de análisis historiográficos específicos que aborden la comparación por distritos de un indicador cualitativo tan importante como las condiciones de la vivienda. El que en los barrios y distritos pobres (donde se enferma y se muere más) existan unas peores condiciones de vida y de alojamiento, resulta una obviedad que casi no necesita demostración. La denuncia de tal situación - y las propuestas de solución - constituye, como estamos viendo, una tradición del discurso higienista, pero no estará de más que hagamos alusión a estudios médico-sociales que, en el tránsito del siglo XIX al XX, ofrecieron información detallada sobre el problema de la vivienda en los distintos distritos madrileños.

Resulta imprescindible mencionar, en este sentido, las aportaciones realizadas por $\mathrm{Ph}$. Hauser en su Madrid bajo el punto de vista médico-social (1900), porque sus datos, minuciosamente recogidos y analizados, nos permiten conocer la situación real de las condiciones de las viviendas madrileñas e, incluso, establecer la correlación entre los barrios más hacinados e insalubres de Madrid y los de mayor mortalidad.

$\mathrm{Ph}$. Hauser lleva a cabo un recuento, por distritos, de las casas colectivas de Madrid, con el fin de valorar el hacinamiento de las distintas áreas geográficas madrileñas. Denomina casas colectivas, las «habitadas por numerosas familias pobres, ocupando una o más piezas pequeñas, sucias, con escasa cubicación de aire y mala ventilación, situadas a lo largo de un corredor y teniendo todos o la mitad de los inquilinos de un piso un retrete común y sin agua». Casas que, insiste Hauser, «representan el mefitismo urbano y son conocidas bajo el nombre de viviendas insalubres» ${ }^{33}$. A su vez, estas casas colectivas pueden considerarse de dos tipos: 1) casas

30 Véase el ya citado trabajo de GARCíA GÓMEZ-ÁLVAREZ (1992).

31 FÉRNANDEZ, A. (1992), «Clase obrera y tuberculosis en Madrid a principios del siglo XX», En HuERTAS, R. y CAMPOS, R. (coords.), Medicina Social y clase obrera en España (siglos XIX y XX), Madrid, FIM, t.I., pp. 93-124.

32 PORRAS (1997). Una aportación fundamental en relación a toda esta problemática es el reciente trabajo de Porras, M.I. (2002), «Un acercamiento a la situación higiénico-sanitaria de los distritos de Madrid en el tránsito del siglo XIX al XX», Asclepio, 54 (1), 219-250.

33 HAUSER (1900), t.I, p. 322. 
de vecindad, «habitadas por la clase obrera o indigente, que no cuenta sino con un salario mezquino o con medios insuficientes para satisfacer el alquiler de una vivienda decente»; y 2) casas de dormir, cuyas habitaciones encierran un número indeterminado de camas o jergones y están destinadas a recibir, por noches, a personas sin domicilio, a un lumpen compuesto, según expresión del propio Hauser, los «desheredados, pertenecientes a la última escala social» ${ }^{34}$.

Encuentra Hauser, en su estudio, que las casas de vecindad se hallaban diseminadas por casi todos los distritos de la capital, aunque distribuidas de manera desigual. El siguiente cuadro es claramente indicativo:

\begin{tabular}{||l|c|c||}
\hline \multicolumn{1}{|c|}{ DISTRITOS } & CASAS & HABITANTES \\
\hline Inclusa & 120 & 15.267 \\
Latina & 89 & 11.553 \\
Universidad & 78 & 8.124 \\
Hospital & 54 & 6.825 \\
Buenavista & 25 & 2.114 \\
Audiencia & 24 & 3.249 \\
Hospicio & 24 & 2.814 \\
Palacio & 23 & 2.387 \\
Centro & 1 & 170 \\
Congreso & - & - \\
\hline TOTAL & $\mathbf{4 3 8}$ & $\mathbf{5 2 . 5 2 1}$ \\
\hline
\end{tabular}

Son exactamente los mismos datos que César Chicote aporta, años más tarde, para ilustrar que «El hacinamiento en las casas llamadas de vecindad o de corredor, es verdaderamente espantoso» ${ }^{35}$. Hacinamiento que se ve agravado por el hecho de que, en dichas casas, no se disponga más que de «una sola fuente para toda la casa y de un solo retrete para cada piso» ${ }^{36}$.

Existe una relación directa entre mortalidad por distritos y condiciones de vivienda y hacinamiento. Los distritos de Inclusa y Latina, precisamente los que cuentan

34 Ibid., p. 323.

35 CHICOTE, C. (1914), La vivienda insalubre en Madrid, Madrid, Ayuntamiento de Madrid, p. 29.

36 Ibidem. Es de notar que dichos datos, que Chicote aporta como propios, son idénticos a los que ofrece Hauser y, con seguridad, deben estar tomados de su obra, sobre todo, si tenemos en cuenta que Chicote los publica en 1905, año en el que ya se había incorporado al mapa administrativo madrileño el distrito de Chamberí que, como puede verse, no aparece en el recuento de Hauser, aparecido en 1900. 
con mayor número de casas insalubres y con más habitantes viviendo en condiciones de hacinamiento, son en los que se registra mayores tasas de mortalidad, si descontamos los fallecimentos producidos en los hospitales. Es interesante constatar cómo el distrito de Hospital (con el Hospital General, el de San Carlos y el del Niño Jesús) y el de Universidad (con el Hospital de la Princesa), presentan una mortalidad muy elevada, a expensas de pacientes que no necesariamente provenían de dichos distritos. Partiendo de datos de Revenga y de Hauser, se ha calculado la mortalidad de los distritos de Madrid en 1900, del siguiente modo:

\begin{tabular}{||l|c|c||}
\hline \multicolumn{1}{|c|}{ DISTRITOS } & Mortalidad general* & $\begin{array}{c}\text { Mortalidad descontando } \\
\text { hospitales* }\end{array}$ \\
\hline Inclusa & 45,7 & 37,9 \\
Latina & 31,7 & 30,2 \\
Universidad & 35,2 & 31,2 \\
Hospital & 72,5 & 29,2 \\
Buenavista & 24,4 & 22,8 \\
Audiencia & 26,2 & 26,2 \\
Hospicio & 29,4 & 28,4 \\
Palacio & 26,3 & 24,6 \\
Centro & 19,8 & 19,6 \\
Congreso & 20,6 & 20,2 \\
\hline
\end{tabular}

*Tasas por 1000 habitantes.

Si consideramos mortalidad por patologías (tuberculosis, viruela, sarampión, tifoideas, etc.) los distritos de mayor mortalidad son siempre Inclusa, Latina, Hospital y Universidad, donde más viviendas insalubres existían y donde las condiciones urbanísticas eran peores. Distritos que, además, se distinguían por sus focos de insalubridad urbana. El primero, «además de encerrar numerosos establecimientos de aglomeración humana, tales como la Inclusa y la Maternidad, La Fábrica de Tabacos, el Colegio de la Paz, el Asilo de niños de cigarreras, contiene el famoso mercado de objetos viejos conocido con el nombre el Rastro (...) sus casas son viejas, muchas en ruina, desprovistas de luz y aire, y habitadas en gran parte, por familias habituadas a la suciedad y al desaseo, careciendo de toda noción de higiene» ${ }^{37}$.

\footnotetext{
37 HAUSER (1900), t. I, p. 319.
} 
En Hospital y Universidad, los hospitales ya citados eran considerados como focos de infección para los barrios colindantes, no solo por las penosas condiciones higiénicas de los establecimientos, sino porque era práctica habitual vender la ropa de los fallecidos (enfermos infecciosos en muchos casos) a los habitantes de las proximidades.

A todo ello hay que añadir otros dos focos de insalubridad urbana: la existencia de muladares en la proximidad de las calles habitadas y el número considerable de pozos negros en las calles desprovistas de alcantarillado. Según los datos de Hauser, Latina es el distrito que más muladares albergaba —un total de 37-, siendo la ausencia de alcantarillado más desigual. Llama la atención, sin embargo, que Centro (una sola calle sin alcantarillado y ningún muladar) y Congreso (doce calles sin alcantarillado y un solo muladar) siguen siendo, también en este capítulo, los distritos mejor dotados desde el punto de vista higiénico ${ }^{38}$.

Ya en la segunda década del siglo XX, podemos encontrar otro documento, a mi juicio, de incuestionable importancia a la hora de valorar el interés de los higienistas madrileños por el problema de la vivienda. Se trata de La vivienda insalubre en Madrid, memoria presentada en 1914 por César Chicote, director del Laboratorio Municipal, al Ayuntamiento de Madrid por encargo expreso de su alcalde, el Vizconde de Eza. Los trabajos de desinfección llevados a cabo por el Laboratorio Municipal, dieron la posibilidad a Chicote de obtener información de «casi todas las casas de Madrid», por lo que en su informe hay muchas alusiones a casas concretas. «Son muy numerosas» - escribe - «las casas que ha visitado el personal de desinfección, que reúnen entre 200 y 300 habitantes, sobre todo en los distritos de Hospital, Inclusa y Latina, así como lo han sido en buen número las que rebasan esta última cifra, pudiendo citar, entre otras, las que siguen, por la repetición que en ellas se han observado de casos de enfermedades ${ }^{39}$ :

Los datos son de 1907 y están tomados por el propio Chicote de la Memoria del Laboratorio Municipal de dicho año. Los inmuebles citados, catalogados como los más insalubres de Madrid, eran casas de vecindad o de corredor, en las que el hacinamiento se consideraba el responsable directo de una mortalidad que, según el autor del informe, alcanzaba el 30-50 por 1000.

Distingue Chicote con finura entre hacinamiento y densidad de población, explicando sus diferencias y la interpretación sanitaria que de ambos conceptos debe hacerse. La comparación entre el distrito Centro y «los del Sur» es suficientemente elocuente: «...en el distrito Centro, cuya mortalidad es de las más bajas y en donde la densidad es mayor - correspondiendo a sus habitantes solamente 13 metros cuadrados para cada uno- se disfruta del beneficio de que cada familia viva en un cuarto

38 HAUSER (1900), t. I., p. 334

39 Chicote (1914), p. 30. 
más o menos amplio, pero con entera separación e independencia y compuesto de varias habitaciones y dormitorios, ocupados sólo por una o dos personas cuando más; y por esta causa, su mortalidad es baja (...) En cambio, en el distrito de la Inclusa, por ejemplo, o en el de Hospital, la extensión superficial para cada habitante es mucho mayor (35 y 36 metros cuadrados, respectivamente); pero como en ellos existe un verdadero hacinamiento, la mortalidad aumenta considerablemente» ${ }^{40}$. El argumento no sirve solo para la mortalidad general, sino para la mortalidad por tuberculosis, la gran enfermedad social de la época, cuya relación con el hacinamiento estaba más que documentado ${ }^{41}$, hasta el punto de, entre otros muchos, recibir el apelativo de «enfermedad de la vivienda ${ }^{42}$.

\begin{tabular}{|c|c|}
\hline SITUACIÓN & $\mathrm{N}^{\circ}$ HABITANTES \\
\hline Paseo de la Delicias, $\mathrm{n}^{\circ} 7$ & 376 \\
\hline Paseo de Santa María de la Cabeza, $n^{\circ} 10$ & 321 \\
\hline Calle de Méndez Alvaro, $\mathrm{n}^{\circ} 16$ & 625 \\
\hline Calle de Lavapiés, $\mathrm{n}^{\circ} 36$. & 335 \\
\hline Calle de Pacífico, $\mathrm{n}^{\circ} 32$ & 320 \\
\hline Plaza de Lavapiés. & 450 \\
\hline Calle del Olivar, $\mathrm{n}^{\circ} 15$. & 406 \\
\hline Carrera de San Francisco, $\mathrm{n}^{\circ} 8$. & 345 \\
\hline Ronda de Valencia, $\mathrm{n}^{\circ} 10$. & 340 \\
\hline Ronda de Segovia, $\mathrm{n}^{\circ} 11$. & 493 \\
\hline Ronda de Segovia, $\mathrm{n}^{\circ} 13$. & 340 \\
\hline Ronda de Segovia, n $^{\circ} 37$. & 765 \\
\hline
\end{tabular}

C. Chicote termina su informe con un análisis de las «Chozas, casuchas y cuartelillos» existentes en «los límites de las barriadas extremas de Madrid». Denuncia el chabolismo por insano y da cuenta de las miserables condiciones de vida en barriadas como Peñuelas, Salitre, el Cristo de la Injurias o Santa María de la Cabeza (con una mortalidad del 37,83\%.) que, si se recuerda, ya habían sido nombradas por Casas Batista y Méndez Álvaro en 1874, y cuyas condiciones no parecían haber cambiado en cuarenta años. Chicote enumera también otras chabolas

40I Ibidem.

41 FERnÁndez, A. (1992); MOLero, J. (1989), Historia social de la tuberculosis en España (18891936), Granada, Tesis Doctoral.

42 De hecho, entre 1911 y 1914 se recogen datos para un Primer ensayo de un padrón tuberculoso de Madrid. Una fuente imprescindible, en este sentido, es CoDINA, J. (1916), El problema social de la Tuberculosis en Madrid, Madrid, Imp. Enrique Teodoro. 
en cuarenta años. Chicote enumera también otras chabolas y «casuchas» construidas más al interior de la ciudad como las de la calle Toledo, Arganzuela, Peña de Francia, Rodas, Tribulete, Lavapiés, etc., que venían a sumar insalubridad a los distritos, tantas veces mencionados, de Hospital, Inclusa y Latina ${ }^{43}$.

\section{LA VIVIENDA HIGIÉNICA}

Es evidente que la constatación de una realidad sanitaria y social tan dura como la reseñada, obligaba a intervenir sobre ella de manera contundente. No es mi intención analizar en profundidad las propuestas y realizaciones de política urbanística y de vivienda que tuvieron lugar en Madrid, durante los años de nuestro estudio, pero sí hacer alusión, siquiera brevemente, a las que, en mi opinión podrían considerarse las más destacadas iniciativas surgidas o apoyadas en el seno del higienismo madrileño.

En general, podemos decir que dicho discurso higiénico responde y se identifica metodológica e ideológicamente con los principios de la Higiene «liberal» de finales del XIX y comienzos del XX: reconocimiento de la naturaleza social de la enfermedad, recurso a la experiencia personal, empleo de la encuesta sanitaria y sometimiento a los límites de la economía política libera ${ }^{44}$. Es el liberalismo - más moderado o más radical según los casos - el que hace que, desde el punto de vista ideológico, la preocupación por el menesteroso se haga siempre desde presupuestos burgueses en los que se aunan, invariablemente, la defensa social y el paternalismo de la clase dominante. Un ejemplo suficientemente elocuente de esta tendencia puede encontrarse ya en Méndez Álvaro cuando, en un apartado de su tantas veces citado discurso al que titula «Hasta qué punto conviene y es realizable una ventajosa reforma en la habitación de las clases necesitadas», insiste en que «Todas las clases sociales se hayan vívamente interesadas en la mejora de la habitación del pobre; por cuanto las poblaciones, como las familias, están sujetas (...) a causas comunes de insalubridad, a enfermedades colectivas (...) Si en las insalubres casas de los menesterosos toman con facilidad mucho mayor origen las enfermedades llamadas con razón populares, poco tardan luego en irradiar desde aquellos focos hasta los palacios de los príncipes, abrazando el conjunto de la población. En tales casos es necesario que la defensa sea

43 Chicote (1914), p.58.

44 Véase Coleman, W. (1982), Death Is a Social Disease. Public Health and Political Economy in Early Industrial France, Madison, The University of Wisconsin Press. Esteban Rodríguez Ocaña ha utilizado, con acierto, dichos elementos para identificar la labor de Ph. Hauser pero, naturalmente, puede extenderse con más o menos exactitud, a la mayoría de los higienistas españoles de la época. $C f$. RODRIGUEZ OCAÑA, E. (1996), «La encuesta sanitaria como contribución original de Philipp Hauser a la Salud Pública española», en CARRILlo, J.L. (ed.), Entre Sevilla y Madrid. Estudio sobre Hauser y su entorno, Sevilla, pp. 194-210. 
común; porque el hombre, cuando vive en sociedad, como lo exige su naturaleza, tiene que ser siempre solidario así de los bienes como de los males propios de la asociación» ${ }^{45}$. Se apresura a aclarar que las mejoras de las condiciones de vida de las clases populares no deben, bajo ningún concepto, considerarse «como una concesión emanada de un derecho»; su punto de vista no deja lugar a dudas, con respecto a las reformas e higienización de las viviendas obreras: «no se suponga que es un deber de la sociedad para con determinadas clases, sino solamente una justa y razonable aspiración al bien general: no se vea en ese hecho a la sociedad que se disuelve en el más vergonzoso y repugnante socialismo, sino a la sociedad que se regenera, que se une y concentra, que fortifica y estrecha sus fraternales lazos, oponiendo un vigoroso aunque blando y discreto dique, a las fuerzas brutales que tienden a disolverla.... $\rangle^{46}$.

Paternalismo burgués, desconfianza hacia el socialismo, intento de dilución de la «lucha de clases», defensa social tanto ante el peligro epidémico como ante el revolucionario,... Elementos que no hacen sino corroborar las palabras de F. Engels cuando, al referirse concretamente al problema de la vivienda, señala que: «Estas epidemias se extienden entonces a los barrios más aireados y más sanos en que habitan los señores capitalistas. La clase capitalista dominante no puede permitirse impunemente el placer de favorecer las enfermedades epidémicas en el seno de la clase obrera, pues sufriría ella misma las consecuencias (...) Desde el momento en que quedó científicamente establecido, los burgueses humanitarios se encendieron en noble emulación para ver quien se preocupaba más por la salud de sus obreros. Para acabar con los focos de origen de las constantes epidemias, fundaron sociedades, publicaron libros, proyectaron planes, discutieron y promulgaron leyes. Se investigaron las condiciones de habitación de los obreros y se hicieron intentos para remediar los males más escandalosos $»^{47}$.

Las palabras de Engels pueden ser superponibles a la realidad española, y madrileña, que estamos analizando y muy pronto iniciativas estatales, municipales y particulales se daran cita para abordar la «cuestión de la vivienda» como parte de la «cuestión social». No deja de llamar la atención, sin embargo, que en las conclusiones del Congreso de Higiene de 1882, se achacara la mala salud de los madrileños a aspectos de higiene pública general, siendo la alusión a las diferencias de clase social muy restringida: el clima desfavorable de Madrid, la densidad de la población, la excesiva altura de los edificios, las malas condiciones de las alcantarillas, la permeabilidad excesiva del suelo y las deficientes condiciones higiénicas de los mercados y hospitales fueron, a juicio de los expertos, las razones fundamentales de la mortalidad y mala salud de los habitantes de la Villa, en su conjunto. De manera que para

45 MÉndez Álvaro (1874), p. 259.

46 Ibid., p. 258.

47 ENGELS, F. [1872] (1975), «Contribución al problema de la vivienda», En MARX, K y ENGELS, F. Obras escogidas, Madrid, Fundamentos, t. I., pp. 607-608. 
modificar algunos de estos factores, y proteger a la población «en su conjunto», era necesario intervenir sobre los focos de insalubridad, perfectamente identificados en las casas y barriadas populares.

A este respecto, y junto a medidas de saneamiento público, las iniciativas específicas sobre las viviendas pueden resumirse, básicamente, en dos: por un lado, la construcción de casas baratas, destinadas a obreros y «clases modestas», según los principios de la Higiene y, por otro, las reformas urbanísticas que acometan las demolición de casas y barrios insalubres, y su sustitución por inmuebles e infrestructuras más adecuadas.

La mayoría de nuestros médicos sociales revisan, en sus escritos, las tendencias y realizaciones extranjeras en materia de «casas baratas», argumentando la utilidad de las mismas. La demanda a Ayuntamientos o a sociedades y cooperativas privadas para que acometan este tipo de construcciones es prácticamente constante, sin embargo, las posibilidades que se barajan para que las «clases menesterosas» puedan optar a una vivienda digna son diversas y sujetas, en ocasiones, a un debate intenso. Federico Montaldo, en una conferencia pronunciada en el Círculo de la Juventud Democrática en 1905, enumera dichas posibilidades del siguiente modo:

«1. Cuartos o habitaciones en pisos de grandes edificios, para muchas familias;

2. Casas mixtas, o sea sotabancos o interiores de casas de los ricos o burguesas.

3. Casas independientes, solas o agrupadas, formando barrios, para una familia cada una; y

4. Cuartos para solteros, hembras o varones, en casas amuebladas con comedor, baños y otros servicios generalmente comunes ${ }^{48}$.

Estas cuatro opciones son objeto de debate entre los higienistas. Para Méndez Alvaro, «esos colosales edificos que se han llamado ciudades obreras, han de ser siempre y necesariamente, una amenaza, un peligro para la totalidad de las poblaciones ${ }^{49}$. Hauser, por su parte, elogia la «casa obrera colectiva» construida por «La Constructora Benéfica» en la calle Solana, números 13 y 15 (en el distrito de Inclusa). «La casa» - explica- «tiene un bajo, cuatro principales, cuatro segundos y cuatro terceros, dos tiendas y cuatro sótanos alquilables; además 15 buhardillas trasteras y el local destinado a portería. Cada cuarto tiene cuatro habitaciones, cocina y retrete con agua» ${ }^{50}$. La casa en cuestión estaba destinada a quince familias y, asegura Hauser, «las buenas condiciones de luz, de aire, de agua, de limpieza y de confortabilidad de los cuartos ${ }^{51}$; haciendo constar, sin embargo, que se trata de un edificio

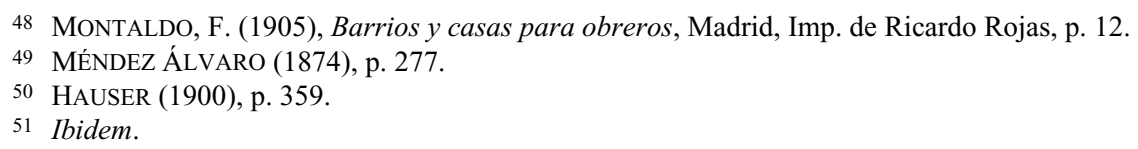


aislado, rodeado de casas insalubres y situada en una calle de gran hacinamiento y suciedad, por lo que critica su ubicación y recomienda planes integrales que la iniciativa privada, más o menos filantrópica, no es capaz de cubrir.

Sin embargo, el debate más profundo surge entre los barrios obreros, formados por casas independientes y unifamiliares, y las casas mixtas en las que convivan, suficientemente jerarquizadas, distintas clases sociales. En el Primer Congreso Nacional de Arquitectura celebrado en Madrid en 1883, se abordó con amplitud esta cuestión, quedando perfectamente perfiladas las dos posiciones extremas: por un lado, la que defendía la construcción de barrios obreros de casas unifamiliares en el extrarradio de la ciudad, estimulando el acceso del trabajador a una propiedad; y, por otro, la que se oponía a la construcción de dichos barrios por entender que la separación del proletariado del resto de la población favorecía el antagonismo social y el socialismo ${ }^{52}$. Frente al diseño y construcción de barrios obreros, se propugna la convivencia en el mismo edificio de burgueses y obreros, considerándose, dicha convivencia, un factor fundamental no solo de la desmovilización social, sino de la reforma de costumbres y de la integración en la norma social burguesa de los trabajadores y sus familias. Ricardo Campos, estudiando el problema del alcoholismo, ha puesto de manifiesto, a mi juicio con gran acierto, de qué manera el debate sobre la vivienda obrera trascendió a otros ámbitos de la higiene social, de la moralización del obrero y de la asunción, por su parte, de hábitos higiénicos y acordes con las costumbres, reglas y valores de la clase dominante ${ }^{53}$.

Existen numerosos textos de la época en los que, con argumentaciones higiénicomorales, se insiste en los «buenos resultados» de esta convivencia: «En contacto forzoso todos, se conocerían y se estimarían: el obrero vicioso tendría un freno en el qué dirán de sus vecinos: si venía beodo temería encontrarse en la escalera a la señora del segundo que atendió a su mujer en el último parto con su regalito, o al médico que la atendió gratuitamente o al del tercero, que le da ropita usada de los niños (...) Si se encuentra sin trabajo se atreverá por medio del portero, a pedir una recomendación al señor del principal y como necesitará hablar con éste, se esforzará para aparecer limpio y porque su lenguaje sea correcto, para lo cual buscará medios de instruirse» ${ }^{54}$.

Sin embargo, la división administrativa y social de las ciudades había quedado sancionada por las autoridades que debían hacer frente al aumento de población derivado de las abalanchas inmigratorias que acudían a una ciudad en proceso de indus-

52 Sobre los debates en el mencionado Congreso de Arquitectura, véase DíEZ DE BALDEÓN, C. (1986), Arquitectura y clases sociales en el Madrid del siglo XIX, Madrid, Siglo XXI, pp. 428 y ss.

53 CAMPOS, R. (1994), «Casas para obreros. Un aspecto de la lucha antialcohólica en España durante la Restauración», Dynamis, 14: 111-130.

54 REPLlÉS y VARGAS, E. (1892), El obrero en la sociedad, Madrid, Imp. litográfica de los Huérfanos, p. 33. Parecidos argumentos se encuentran en obras como la de ElolA, P.L. (1909), Casas baratas para obreros, Madrid, Imp. Gutemberg-Castro y Cia. 
trialización ${ }^{55}$. Por eso, el sistema de casas «mixtas» muy pronto se convirtió en una reivindicación del pasado que, en las primeras décadas del siglo XX, resultaba ya imposible retomar. El Vizconde de Eza se lamenta, nostálgico, cuando afirma en 1914 que «Han pasado por desgracia aquellos tiempos (...) en que en una misma casa habitaban pobres y ricos (...) La higiene de los unos afectaba a los otros, toda vez que vivían en común, y en la misma forma los resolvían; y así como no había calamidad de los de la guardilla (sic) de que no tuvieran conocimiento los vecinos de los pisos más bajos apresurándose a subir socorro en especie o en metálico, del mismo modo tenía tan cerca el inquilino acaudalado al pobre habitante de los pisos altos, que no había en aquel sistema de sotabanco agudas manifestaciones de insalubridad. Esto ha desaparecido, a mi entender, con gran equivocación social» ${ }^{56}$.

Paternalismo burgués, una vez más, en el marco de una clara jerarquización social que no impidió que en este tipo de casas - cosa que parecen ingorar o silenciar nuestros pro-hombres- la tuberculosis o el cólera, afectara de manera desigual a los habitantes de un mismo edificio, haciéndose presente en los sótanos o en los sotabancos y viéndose libres los habitantes de los pisos principales ${ }^{57}$.

Mención especial merece el barrio de ensanche conocido con el nombre de Ciudad Lineal, diseñado por Arturo Soria y construido por una sociedad cooperativa llamada «Compañía Madrileña de Urbanización» ${ }^{58}$. Las novedades aportadas son diversas: 1) novedades urbanísticas: de calles anchas y paralelas, con facilidad para instalar con rapidez y economía los servicios municipales y de gobierno; 2) novedades de diseño arquitectónico: viviendas unifamiliares construidas en solares edificables solo en su quinta parte, garantizando así la existencia de una parcela para huerta o jardín; y 3) novedades de organización social: al ser un barrio en el que se permite «vivir juntos, a corta distancia unos de otros, a los pobres, a los ricos y a la burguesía, pero no atados a la misma escalera y superpuestos, sino en hogar independiente y libre» ${ }^{59}$.

En total consonancia con las tendencias apuntadas, termina Hauser recomendando que, para dar una solución satisfactoria al problema de la vivienda, se precisa la acción conjunta de varios agentes sociales: Estado, Municipios e iniciativa privada. Las funciones del Estado a este respecto serían: 1) Dictar los reglamentos de la higiene urbana, indispensables para el saneamiento del suelo de las calles y de las casas de

55 Véase MARTíneZ de PISÓN, E. (1964), «La formación de los suburbios madrileños en el paso del siglo XIX al XX», Boletín informativo de Derecho Politico, 31: 42-58.

56 EZA, Vizconde (1914), «Prólogo» a CHICOTE, C., La vivienda insalubre en Madrid, Madrid, Ayuntamiento de Madrid, p. 17.

57 FERNÁNDEZ (1985) y (1992).

58 SORIA, A. (1894), Compañía Madrileña de Urbanización. Conferencia dada en el Ateneo Científico y Literario de madrid acerca de la Nueva Arquitectura de las ciudades, Madrid.

59 HAUSER (1900), p. 363. 
todos los distritos de la ciudad; 2) Suprimir o atenuar todas las cargas o impuestos que pesan sobre las casas habitadas por la clase obrera; y 3) Construir casas higiénicas y baratas para sus empleados cargados de familia y que disfrutan de un sueldo reducido.

En relación con el primer punto, es de destacar que la Ley de sanidad de 1855, modificada en 1886, indicaba en su artículo 98 que «las reglas higiénicas a que están sujetas todas las poblaciones del Reino serán objeto de un reglamento especial, que publicará el Gobierno a la mayor brevedad, oyendo antes al Consejo de Sanidad». Tal reglamento, apostilla Hauser en 1900, «no ha llegado aún a redactarse» ${ }^{60}$.

En el ámbito local, se propone que los Municipios sean los encargados de la ejecución escrupulosa de los reglamentos de higiene urbana y de nombrar inspectores que vigilen el cumplimiento de las normas higiénicas a la hora de construir o alquilar una vivienda. En Madrid, tras las Ordenanzas municipales de 1892, la novedad más importante en el tema que nos ocupa es la creación en 1905 del servicio de empadronamiento sanitario de las viviendas. Servicio que, a semejanza del de Bruselas y París, suponía «el único medio de llegar a un conocimiento completo de las habitaciones insalubres, de las que son corregibles y de las que no admiten remedio alguno» ${ }^{61}$.

La Ley del 12 de junio de 1911, sobre Construcción de casas baratas es, quizá, el texto legislativo más relevante de la época. Debió ser bastante poco efectivo, a juzgar por las palabras de César Chicote cuando afirma con contundencia que «Ni antes ni después de la ley de 12 de junio de 1911, relativa a la Construcción de casas baratas, se ha hecho nada por el Estado en pro del mejoramiento de la vivienda» ${ }^{62}$; sin embargo, en lo relativo a la intervención de los Ayuntamientos, dicha Ley especifica, en su artículo 28, que «Denunciada (...) la existencia de una o varias casas de vecindad o de un grupo de viviendas que por sus malas condiciones constituyan un peligro grave para la salud de la población en general, y de los que las habitan especialmente, el Ayuntamiento podrá proceder a su mejora y saneamiento». Texto que, en el caso de Madrid, vino a complementarse con un bando de la Alcaldía Presidencia, fechado el 3 de julio de 1913, en el que se dispone que «Influyendo notoriamente en el exceso de morbilidad y mortalidad las condiciones antihigiénicas de las viviendas, serán declaradas insalubres y desalojadas aquellas que superen la cifra que representa la mortalidad media de Madrid, para la inmediata adopción de las medidas que se estimen oportunas en cada caso, y, asimismo, las que reconocidamente carezcan de las condiciones de higiene necesarias para la vida».

El vizconde de Eza, alcalde de Madrid en esos años, se muestra dispuesto a «dictar reglas enérgicas acerca del saneamiento de aquellas casas y de aquellas barriadas y aún distritos, que carezcan de las condiciones que exige la higiene moderna, y es para mí principio de necesaria aplicación al presente, el de declarar la expropiación o

\footnotetext{
60 Ibid., p. 357.

61 CHICOTE (1914), p. 97

62 Ibid., p. 89.
} 
demolición forzosa por causas de insalubridad» ${ }^{63}$. Esta demolición de casas e, incluso, de barrios enteros tiene que ver no solo con las condiciones de hacinamiento en el interior, sino con las dificultades de luz y ventilación que, debido a la estrechez de las calles y a la altura de los edificios, presentaban algunas de las barriadas más insalubres. Méndez Álvaro pide, en 1874, una «revisión detenida» de las ordenanzas municipales en lo tocante a la construcción de viviendas ya que «excesiva es evidentemente la elevación que se da en Madrid a las casas (...) mereciendo notarse que la desproporción de su altura es tanto mayor cuanto más reducido en ancho de sus calles» ${ }^{64}$.

Algo parece haberse adelantado a este respecto en las primeras décadas del siglo $\mathrm{XX}$, cuando se asegura que «Es indudable que en Madrid las casas higiénicamente defectuosas se van modificando mediante reformas beneficiosas o desaparecen para resurgir de calles a la morisca, amplias vías que, permitiendo el paso a torrentes de aire y luz solar,llevan la salud a donde antes no existía. Y lo es también que las casas nuevas constrúyense con arreglo a las exigencias de la higiene, salvo en algunos casos en cuanto se relaciona con su altura y anchura de las calles donde se edifican» ${ }^{65}$. Ejemplos suficientemente significativos de este tipo de mejoras radicales con demolición de manzanas enteras, son la desaparición del «islote de casuchas» denominado Tapón del Rastro, y, sobre todo las obras de la Gran Vía madrileña, cuyo trazado afectó a cuarenta y ocho calles e hizo desaparecer totalmente catorce de las consideradas más insalubres, con un total de 315 casas. Tal proyecto de trazado de la Gran Vía debía, en opinión de César Chicote, «aplaudirse sin reservas porque ha de proporcionar a Madrid un indiscutible beneficio de orden sanitario» ${ }^{66}$.

Es evidente, sin embargo, que la «Reforma de la Prolongación de la calle Preciados» pretende dar respuesta a cuestiones no estrictamente sanitarias. Para J.C. Rueda, «la Gran Vía es, ante todo, la solución ante la que se percibe como apabullante crisis de trabajo en la coyuntura descrita entre 1898 y $1909 »{ }^{67}$, de tal modo que el impulso del Ayuntamiento a una obra de tal envergadura vendría a retomar el tradicional papel del Consistorio a la hora de habilitar mecanismos de emergencia ante la retracción de la oferta privada (crisis del negocio inmobiliario) o las tensiones en el mercado de trabajo local. Pero el alcance de este proyecto de remodelación urbana es mucho más complejo; no podemos olvidar que, precisamente, en la Gran Vía se articula un nuevo e importante escenario económico y de consumo, como el representado por las distintas sociedades mercantiles que instalan su sede en los suntuosos edificios, así como por los hoteles y comercios de lujo, los grandes almacenes o las flamantes

63 EZA (1914), p. 12.

64 MÉNDEZ Álvaro (1874), p. 246.

65 Chicote (1914), p. 21

66 Ibid., p. 97.

67 RUEDA, J.C. (1993), «Limitaciones municipales e intereses de reforma. El ejemplo de la Gran Vía madrileña, 1901-1923», Anales del Instituto de Estudios Medrileños, 33: 651-671, p. 652. 
salas de cinematógrafo. En definitiva, un reajuste de usos económicos y residenciales en Madrid que se ajusta y responde con exactitud a lo que algunos autores han definido como «mito urbano», esto es, «un elemento de referencia colectiva que, desde el seno de los sistemas discursivos desarrollados por los poderes públicos (o privados), establece una causalidad directa entre morfologías espaciales y las prácticas de los agentes sociales $\rangle^{68}$.

No obstante, a pesar del conjunto de intereses económicos y políticos que confluyen y se suceden a lo largo de las primeras décadas del siglo en torno a la Gran Vía madrileña, lo cierto es que en el primer proyecto, elaborado por los técnicos municipales José López Sallaberry y Francisco Andrés Octavio, existía todavía una preocupación «higiénica» por descongestionar y sanear la zona urbana correspondiente ${ }^{69}$. De hecho, uno de los objetivos fundamentales de la llamada «Reforma de la prolongación de la calle Preciados y enlace de la plaza del Callao con la calle de Alcalá», respondía a la necesidad de «la construcción de grandes vías que den aire, luz y por consiguiente, higiene a barriadas enteras ${ }^{70}$. No es de extrañar, pues, que tal reforma urbana fuera saludada con vehemencia por los higienistas a pesar de que, como hemos visto, se puedan identificar otros muchos intereses en el trazado y diseño final de esta gran calle.

Sin embargo, a pesar de las aparentes mejoras urbanísticas, las malas condiciones de vida de la clase trabajadora cobraron de nuevo vibrante actualidad con la epidemia de gripe de 1918-19, cuya mortalidad fue especialmente alarmante, una vez más, en los barrios pobres, especialmente «predispuestos» a padecer la enfermedad. En las páginas de El Socialista empiezan a encontrarse textos que hacen clara alusión a la salud de los trabajadores: «Que los trabajadores vivan hacinados en cuchitriles inmundos, adonde no llega la visita vivificadora del sol, en zahurdas sin agua y sin luz, donde los hijos del hombre que debería nacer para alegrar la vida y que apenas nacidos ya van adquiriendo en su semblante la mueca siniestra del hambre (...) hambre que va depauperando una raza, en la que tan fácilmente se pueden cebar todas las enfermedades de carácter epidémico» ${ }^{71}$. No cabe duda, en este sentido, que dicha epidemia supuso un enorme revulsivo para sensibilizar al colectivo médico y a la opinión pública en general de las penosas condiciones sanitarias del país y de la escandalosa falta de organización y de infraestructura sanitaria, pero los tiempos están

\footnotetext{
68 Ibid., p. 652. DAGNUAD, D. (1976), Le mithé de la qualité de la vie et la politique urbaine en France, París.

69 LÓPeZ Sallaberry, J. y ANDrés OCtAVio, F. (1901-1904), Mejoras en el interior de Madrid. Memoria, Madrid.

70 El expediente relativo a la redacción de este proyecto se encuentra en Archivo de la Villa; Sección Secretaría, 33-136-20.

71 El Socialista del 14 de octubre de 1918, n13365, p. 2. Sobre el particular, véase PORRAS, M.I. (1992), «La epidemia de gripe de 1918.1919 en la prensa obrera», en HUERTAS, R. y CAMPOS, R. (coords.), Medicina Social y clase obrera en España (siglos XIX y XX), Madrid, FIM, t. I, pp. 125-144.
} 
cambiando y los acontecimientos revolucionarios de 1917 (con la primera huelga general en España) marcan el inicio de novedades significativas en la correlación de fuerzas sociales, que tendrán consecuencias en el ámbito de la salud ${ }^{72}$. La relación entre la vivienda y los barrios insalubres y la epidemia de gripe es perfectamente establecida en los órganos de expresión del movimiento obrero, llegando a formular reivindicaciones de claro contenido higiénico: «Higienizar la población, y especialmente los barrios obreros; construir alcantarillado, sanear viviendas, fomentar la construcción de casas baratas e higiénicas y procurar que los acaparadores no realicen un negocio criminal a costa del hambre.... $\rangle^{73}$.

Aunque algunos autores han señalado, con acierto, la asunción por parte del movimiento obrero de buena parte del discurso higienista tradicional desde momentos muy tempranos ${ }^{74}$, lo cierto es que a partir de las primeras décadas del siglo XX, las organizaciones obreras van cobrando un mayor protagonismo en la configuración de alternativas socio-sanitarias, que alcanzará su punto culminante en la Segunda República ${ }^{75}$.

Con todo, es indudable que a partir de 1921 se produce un cambio definitivo del modelo demográfico madrileño, iniciándose un ciclo de crecimiento caracterizado por un franco distanciamiento de la natalidad con respecto a la mortalidad ${ }^{76}$. Ningún año de este periodo - de 1921 a la guerra civil — ofrece un crecimiento vegetativo negativo y parece lógico suponer que dicha transición demográfica va en paralelo a una transición sanitaria en la que algunos factores determinantes del estado de salud de la población (condiciones de vida, vivienda, alimentación, etc.) debieron verse modificados de manera positiva. Hay que esperar, sin embargo, a los últimos años veinte para observar cambios significativos, por ejemplo, en los hábitos alimentarios, de la población madrileña - en el acceso a los alimentos más bien-, habiéndose documentado un aumento del consumo de carne a partir de 1926 y, en general, un

72 Un destacado análisis sobre el papel de las fuerzas de oposición al régimen de la Restauración es el realizado por MEAKER, G. (1974), La izquierda revolucionaria en España. 1914-1923, Barcelona; En el plano sanitario, puede verse, HuERTAS, R. (1994), «Fuerzas sociales y desarrollo de la Salud Pública en España. 1917-1923», Revista de Sanidad e Higiene Pública, 68: 45-55.

73 El Socialista del 14 de octubre de 1918, nº 3365, p. 2.

74 Véase CAMPOS, R. (1997), «La higiene y el PSOE (1888-1902)», en Actes de les IV Trobades d'Història de la Ciència i de la Tècnica, Alcoi-Barcelona, SCHCT, pp. 281-290. Sobre el mismo fenómeno, aunque referido al problema concreto de la lucha antialcohólica, CAMPOS, R. (1992), «Herencia biológica y medio social en el discurso antialcohólico del socialismo español (1886-1923), en HUERTAS, R. y CAMPOS, R. (coords.), Medicina social y clase obrera en España (siglos XIX y XX), Madrid, FIM, t. I, pp. 67-91.

75 Para una comprensión global de sus elementos resulta imprescindible la tesis doctoral de JIMÉNEZ LUCENA, I. (1995), Cambio político y alternativas sanitarias: El debate sanitario en la II República, Málaga. Puede verse también Huertas, R. (1992), «La concepción de los Servicios Sanitarios Públicos en la II ${ }^{\mathrm{a}}$ República», en HUERTAS, R. y CAMPOS, R. (coords.), Medicina social y clase obrera en España (siglos $X I X y X X)$, Madrid, FIM, t.II, pp. 555-580.

76 FERNÁNDEZ (1989), p. 33. 
descenso de los precios de los artículos básicos ${ }^{77}$. Asímismo, en 1930 tuvo lugar una notable mejora de los servicios sanitarios de matadero y mercados en el control de los alimentos ${ }^{78}$. La relación entre alimentación y niveles de salud no resulta fácil pero constituye, sin duda, un aspecto fundamental para comprender la transición sanitaria a la que nos estamos refiriendo ${ }^{79}$; relación que merecería un estudio detallado, sobre todo para saber en qué medida las supuestas mejoras en la alimentación incidieron sobre las clases más desfavorecidas, única manera de valorar su papel real en las mencionada transición.

A lo antedicho hay que añadir, naturalmente, el papel jugado por los servicios sanitarios en la mejora del estado de salud de la población, no solo madrileña sino española, que debemos relacionar directamente con las reformas organizativas de la sanidad española de los años veinte y treinta. Reformas iniciadas, en el plano legislativo, en 1925 con el Reglamento municipal de Sanidad (Real Decreto de 9 de febrero de 1925) y con el Reglamento de Sanidad provincial de 20 de octubre de 1925, aun cuando no sea hasta la Segunda República cuando se intente poner en marcha una verdadera y profunda reforma sanitaria ${ }^{80}$.

Sin embargo, en cuanto al saneamiento de las viviendas y las reformas urbanísticas, aunque se fueron produciendo cambios importantes que, según expresión de Manuel Azaña, transformaron un «poblachón mal construido» en un «esbozo de gran capital $»^{81}$, los barrios y distritos más desfavorecidos siguieron padeciendo mayor hacinamiento y peores condiciones higiénicas. El problema del alcantarillado es un buen ejemplo de tal situación. En 1922 se prohibe la construcción de pozos negros en Madrid, pero en 1929 seguían existiendo en la ciudad 240 fosas sépticas y 981 pozos

77 FERNÁNDEZ (1989), p. 68.

78 Ibidem. Con anterioridad a esta fecha, la conflictividad social derivada de los problemas de abastecimientos en Madrid, ha sido apuntada por VICENTE, M.T. y FONTECHA, A. (1987), «Abastecimientos en Madrid, 1914-1925», En BAHAMONDE, A. y OTERO, L.E. (eds.), La sociedad madrileña durante la Restauración. 1876-1931, Madrid, Comunidad de Madrid-Alfoz, vol. I, pp. 489-502.

79 Una interesante aportación, desde la demografía histórica, es la de LIVI-BACCI, M. (1987), Ensayo sobre la historia demográfica europea. Población y alimentación en Europa, Barcelona, Ariel.

80 Existe una amplia bibliografía al respecto; un resumen del proceso puede encontrarse en HUERTAS, R. (2000), «Política sanitaria: de la Dictadura de Primo de Rivera a la II ${ }^{\mathrm{a}}$ República», Revista Española de Salud Pública, 74: 37-45.

81 La expresión de Azaña ha sido utilizada por Santos Juliá para ilustrar el concepto de Madrid como «cuidad de transición» en la tercera década del siglo XX. Véase JULIÁ, S. (1989), «De poblachón mal construido a esbozo de gran capital», en BAHAMONDE, A. y OTERO, L.E. (eds.), La sociedad madrileña durante la Restauración. 1876-1931, Madrid, Comunidad de Madrid-Alfoz, vol. I, pp. 137149. Para un análisis pormenorizado de los cambios urbanísticos en el Madrid de la restauración, véase Ruiz Palomeque, M.E. (1989), En BAhamonde, A. y OTERo, L.E. (eds.), La sociedad madrileña durante la Restauración. 1876-1931, Madrid, Comunidad de Madrid-Alfoz, vol. I, pp. 75-101. 
negros, con diferencias tan sumamente notorias como los 438 de Inclusa o los 439 de Latina, frente a los 12 de Palacio o ninguno de Centro ${ }^{82}$.

Madrid se «modernizaba», no solo desde el punto de vista industrial, económico y urbanístico, sino también desde el punto de vista demográfico e higiénico, aun cuando dicha «modernización» no hizo desaparecer, muchas de las deficiencias infraestructurales de la ciudad, ni mucho menos las desigualdades sociales y sanitarias.

82 FERNÁNDEZ (1989), p. 70. Datos de la Dirección de Fontanería y Alcantarillas aparecidos en la Memoria del Ayuntamiento de Madrid de 1929. 